\title{
Effect of Selenium on Carbimazole-Induced Histopathological and Histochemical Alterations in Prostate of Albino Rats
}

\author{
Saber A. Sakr*, Hoda A. Mahran, Amany E. Nofal \\ Zoology Department, Faculty of Science, Menoufia University, Shebin El-kom, Egypt
}

\begin{abstract}
Carbimazole is an antithyroid drug used in treatment of hyperthyroidism. The present study is undertaken to evaluate the effect of carbimazole in prostate of albino rats and the ameliorative role of selenium. Treating rats with carbimazole $(1.35 \mathrm{mg} / \mathrm{Kg} \mathrm{b.w})$ daily for 8 weeks caused distinct histological alterations in prostate gland compared with control group. The epithelial cells of prostatic acini exhibited degeneration. Hyperplasia were projected into the lumens of the prostatic acini or to the outside stroma. Most of the intertubular blood vessels were congested. Histomorphological results showed that the heights of the epithelial cells were significantly reduced and the thickness of smooth muscle layer increased. Prostate gland of animals treated with carbimazole showed gradual decrease in the polysaccharide, protein and nucleic acids contents. These results were time-dependent. Treating animals with carbimazole and selenium showed an improvement in the histological structure as well as histochemical components of the prostate gland. It is suggested that the ameliorative effect of selenium against the histological and histochemical changes induced by carbimazole may be due to its antioxidant properties.
\end{abstract}

Keywords Carbimazole, Selenium, Prostate, Histology, Histochemistry, Rat

\section{Introduction}

Carbimazole is an antithyroid drug widely prescribed for treatment of hyperthyroidism. It is a 3-carbethoxy methimazole derivative, metabolized to methimazole in the liver. Serum thyroxine, thyroid-stimulating hormone and thyrotropin-bindinginhibitory immunoglobulins are decreased after 2, 4 and 6 weeks of carbimazole treatment[1]. Frenais et al.[2] reported that carbimazole is a common oral treatment for hyperthyroidism in cats. On the other hand, the use of carbimazole was associated with various adverse effects. Ali et al.[3] showed that carbimazole produced mild necrosis of renal tubules in rats. Marazuela et al.[4] mentioned that carbimazole was capable of inducing acute pancreatitis and cholestatic hepatitis in 33-year old female. Zaidi et al.[5] reported that carbimazole administration even in therapeutic dose during pregnancy and lactation resulted into alteration of the thyroid microstructure of the newborn. Pulmonary haemorrhage and necrotizing glomerulonephritis were associated with carbimazole therapy[6]. Vilchez et al.[7] reported that carbimazole therapy caused both minor (e.g. pruritus, rash, urticaria, fever and arthralgias) and potentially life-threatening (e.g, agranulocytosis, hepatotoxi-

* Corresponding author:

sabsak@yahoo.com (Saber A. Sakr)

Published online at http://journal.sapub.org/ajmms

Copyright (C) 2012 Scientific \& Academic Publishing. All Rights Reserved city with severe cholestatic jaundice) effects.

Oxidants and antioxidants have attracted widespread interest in nutrition research, biology and medicine. Selenium is an essential element important in many biochemical and physiological processes including the biosynthesis of coenzyme Q (a component of mitochondrial electron transport systems), regulation of ion fluxes across membranes, maintenance of the integrity of keratins, stimulation of antibody synthesis, and activation of glutathione peroxidase[8]. Gärtner[9] reported that the plasma selenium levels indicate the amount of circulating selenoproteins and selenoenzymes which are important for modulating the immune system and also for thyroid hormone metabolism. Sodium selenite is commonly used as a direct supplement for the treatment of selenium deficiency. Selenium had antiperoxidative effect and capacity to prevent cancer[10]. Recent studies have noted an inverse relationship between selenium status and cancer risk in several tissues, including the esophagus, stomach, lung, and prostate[11]. McCormick et al.[12] did not support the hypotheses that selenium is potent cancer chemopreventive agent in the prostate of rat. Liao et al.[13] reported that selenium played a beneficial role for prevention of cisplatin hepatotoxicity in mice. Selenium has a protective effect against rat liver and kidney damage induced by mercury chloride[14] and by cadmium[15]. Sakr et al.[16] found that selenium ameliorated the testicular damage and oxidative stress induced by carbimazole in albino rats. The present work aims to investigate the effect of selenium on the his- 
tological and histochemical alterations induced by carbimazole in prostate of albino rats.

\section{Material and Methods}

\subsection{Animals}

Sexually mature male albino rats(Rattus norvegicus) weighing $125 \pm 5 \mathrm{~g}$ and aged 15 weeks were purchased from the breeding center of experimental animals at Helwan University, Helwan, Egypt. The animals were kept in the laboratory under constant temperature $\left(25 \pm 1^{\circ} \mathrm{C}\right)$ for at least one week before and along the period of the experimental work. They were maintained on a standard rodent diet composed of $55 \%$ corn starch, $20 \%$ casein, $15 \%$ corn oil, $5 \%$ salt mixture and 5\% vitaminized starch (Egyptian Company of Oils and Soap Kafr-Elzayat, Egypt). Water was available ad libitum.

\subsection{Experimental Design}

The animals were divided into 4 groups ( 20 animals each). Group1: animals of this group were served as normal control. Group 2: animals of this group were orally given carbimazole $(1.35 \mathrm{mg} / \mathrm{Kg}$ b.w, equivalent to the therapeutic dose for human[17] ) dissolved in water, daily for 8 weeks. Group 3: animals of this group were orally given sodium selenite (10 $\mu \mathrm{g} / \mathrm{Kg}$ b.w) dissolved in water, daily for 8 weeks. Group 4 : animals of this group were orally administered carbimazole $(1.35 \mathrm{mg} / \mathrm{Kg} \mathrm{b} . \mathrm{w})$ and sodium selenite $(10 \mu \mathrm{g} / \mathrm{Kg}$ b.w)[18] for 8 weeks. All the experiments were done in compliance with the Guide for the Care and Use of Laboratory animals. The treated animals were sacrificed by cervical decapitation after 4 and 8 weeks of treatment.

\subsection{Histological and Histochemical Examination}

Ten rats were sacrificed from treated and control groups after 4 and 8 weeks. Their prostate glands were excised. For histological study, prostate glands were fixed in alcoholic Bouin's fluid, dehydrated in ethyl alcohol, cleared in xylol and embedded in paraffin wax. Sections of five micrometers thickness were cut and stained with haematoxylin and eosin. For histochemical study, specimens were fixed in Carnoy's fluid. Periodic acid Schiff's reaction[19] was used for demonstration of polysaccharides. Total proteins were detected using the mercury bromophenol blue method[20]. Nucleic acids (DNA\&RNA) were determined using Schiff-methylene blue method[21]. The epithelial height and thickness of smooth muscle layer were measured in sections of the acinus stained with $\mathrm{H}$ and $\mathrm{E}$. All data were obtained from 10 random microscopic fields per animal at X 100 objective.

\subsection{Statistical Analysis}

The results were expressed as mean $\pm \mathrm{SD}$ of different groups. The differences between the mean values were evaluated by ANOVA followed by Student's "t" test using
Minitab 12 computer program (Minitab Inc., State Collage, PA).

\section{Results}

\subsection{Morphometrical Results}

Figures $(1 \mathrm{a} \& \mathrm{~b})$ showed the morphometric changes in the epithelial heights and thickness of smooth muscle layer in the prostate acini. Treating animals with carbimazole for 8 weeks showed significant decrease $(\mathrm{P}<0.05)$ in the cell epithelial heights. On the other hand, animals treated with carbimazole and selenium for the same period showed significant increase in the epithelial heights in comparison with carbimazole group. The thickness of the smooth muscle layer increased significantly in rats treated with carbimazole. No significant changes were recorded in heights of epithelial cells or thickness of smooth muscle layer in selenium-treated rats compared with control animals.

A

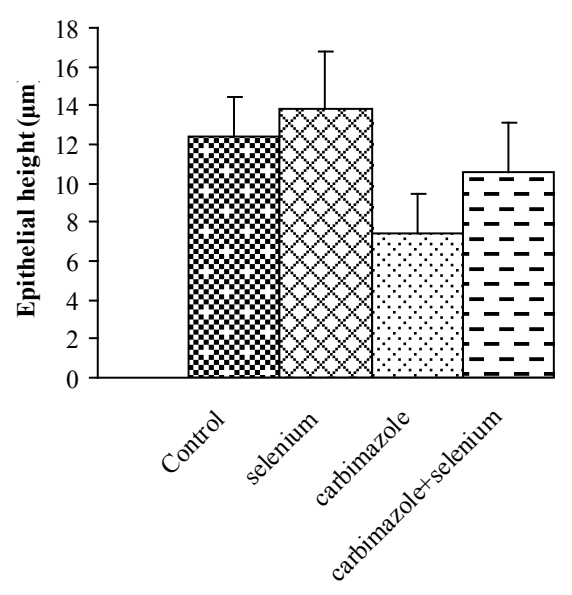

B

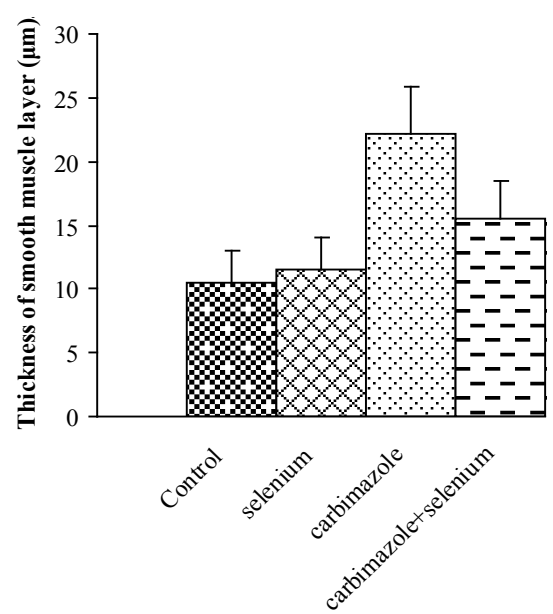

Figure 1. Change in cells epithelial heights (A) and thickness of smooth muscle layers (B) in different animal groups

\subsection{Histopathological Results}




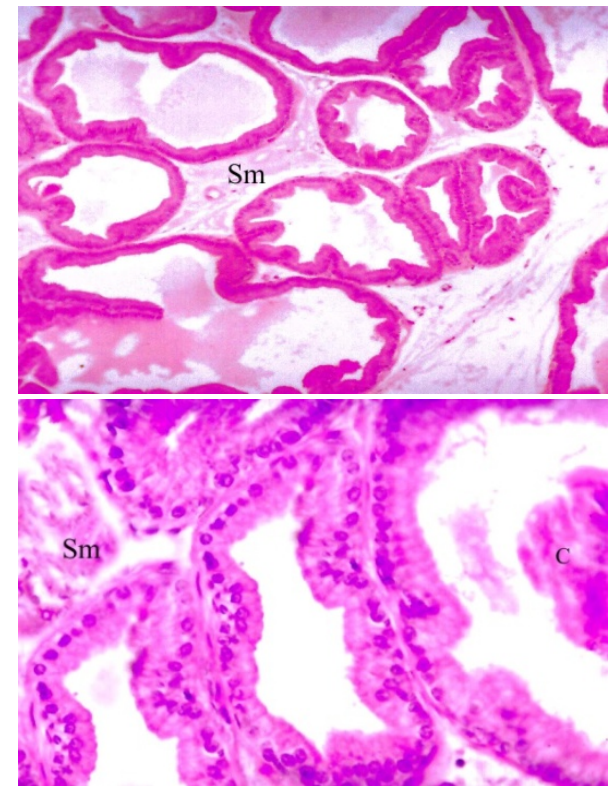

Figure 2. Sections in prostate gland of a control rat showing the normal histological appearance of prostatic acini surrounding by fibromuscular stroma $(\mathrm{Sm})$ and small pink concretion (C) inside their lumens, (a) (H\&E.,X100),(b)(H\&E.,X400)

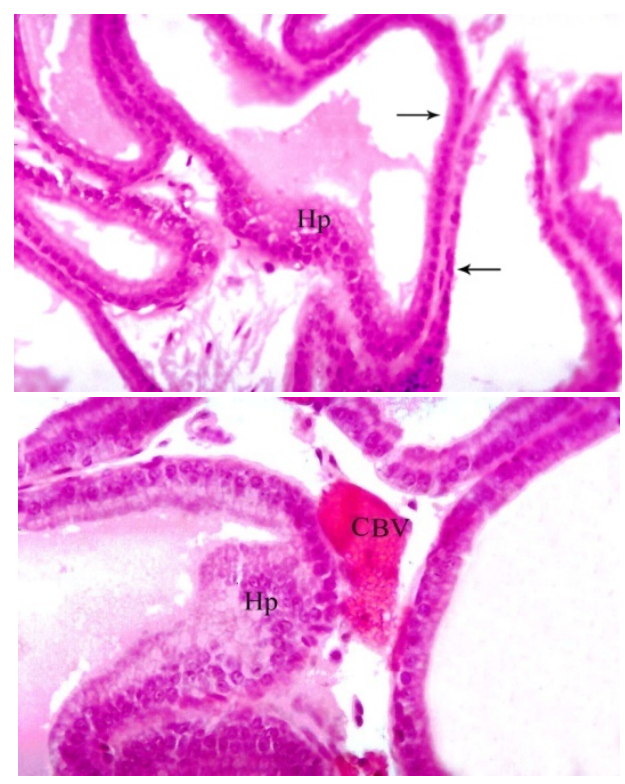

Figure 3. Sections in prostate gland of a rat daily treated with carbimazole for 4 weeks showing (a) hyperplasia (Hp) and flattened epithelium (arrows), (H\&E., X100) and (b) congested blood vessel (CBV), (H\&E., X400)

The prostate gland is an aggregate of numerous tubulo-alveolar acini of different size surrounded by an outer thick capsule. The secretory tubules vary in size, irregular in shape and their lining epithelium were folded with simple columnar or cuboidal cells. The acinus lumen contained prostatic concretions (corpora amylacea). Between the secretory tubules, there is fibromuscular stroma which formed of fibro-elastic tissue, smooth muscle fibers and blood vessels (Figs. 2a\&b). Prostate gland of rats administered with carbimazole for 4 weeks showed many histopathological changes. The prostatic acini were found to be formed of abnormal flattened epithelial layers, large hyperplasia were projected into the lumens of the prostatic acini or to the outside stroma. Most of the intertubular blood vessels were congested (Figs. 3a\&b). Examination of prostate of rats after 8 weeks of the same treatment revealed that the prostatic acini showed marked hyperplasia and thick smooth muscle (Figs. $4 \mathrm{a} \& \mathrm{~b}$ ). Prostate of rats treated with carbimazole and selenium for 8 weeks revealed less prominent histopathological changes when compared with the same period of carbimazole group (Fig. 5).

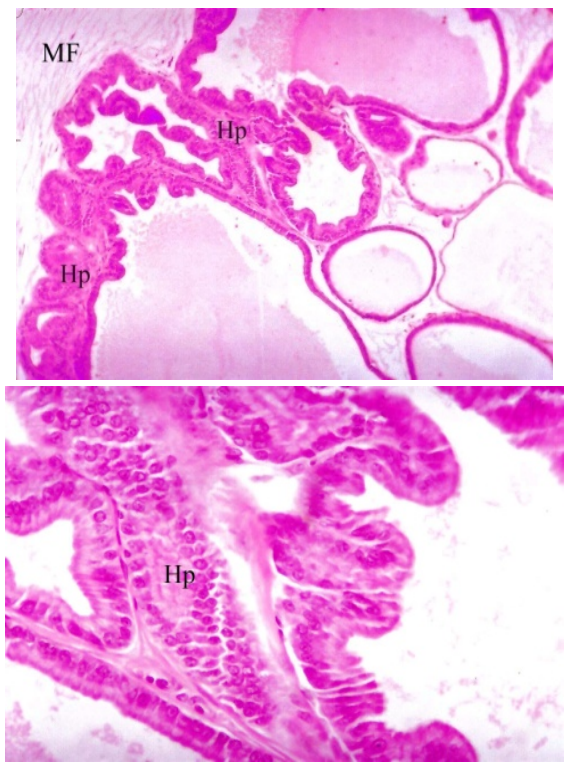

Figure 4. Sections in prostate gland of a rat daily treated with carbimazole for 8 weeks showing hyperplasia (Hp) with thick muscle fibers (MF), (H\&E.,(a) X 100 and (b) X 400 )

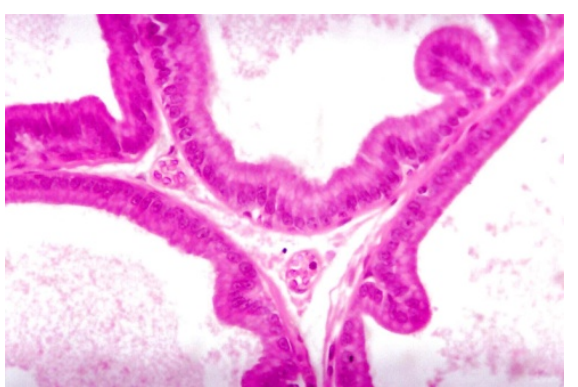

Figure 5. Section of prostatic acini of a rat daily treated with carbimazole and selenium for 8 weeks showing normal acini with normal folded epithelial layers, (H\&E., X 400)

\subsection{Histochemical results}

\subsubsection{Polysaccharides}

Prostate of control rats revealed that the cytoplasm of epithelial layers had a moderate PAS-positive materials while their nuclei were negatively stained. The brush borders of the epithelial layers, prostatic concretion and stroma appeared with strong PAS reaction (Fig. 6a). Prostate of carbimazole-treated animals revealed gradual decrease of PAS-positive materials and reached its maximum after 8 weeks (Fig. 6b). Examination of Prostate glands of rats treated with carbimazole followed by selenium showed an increase of the polysaccharide content (Fig. 6c). 


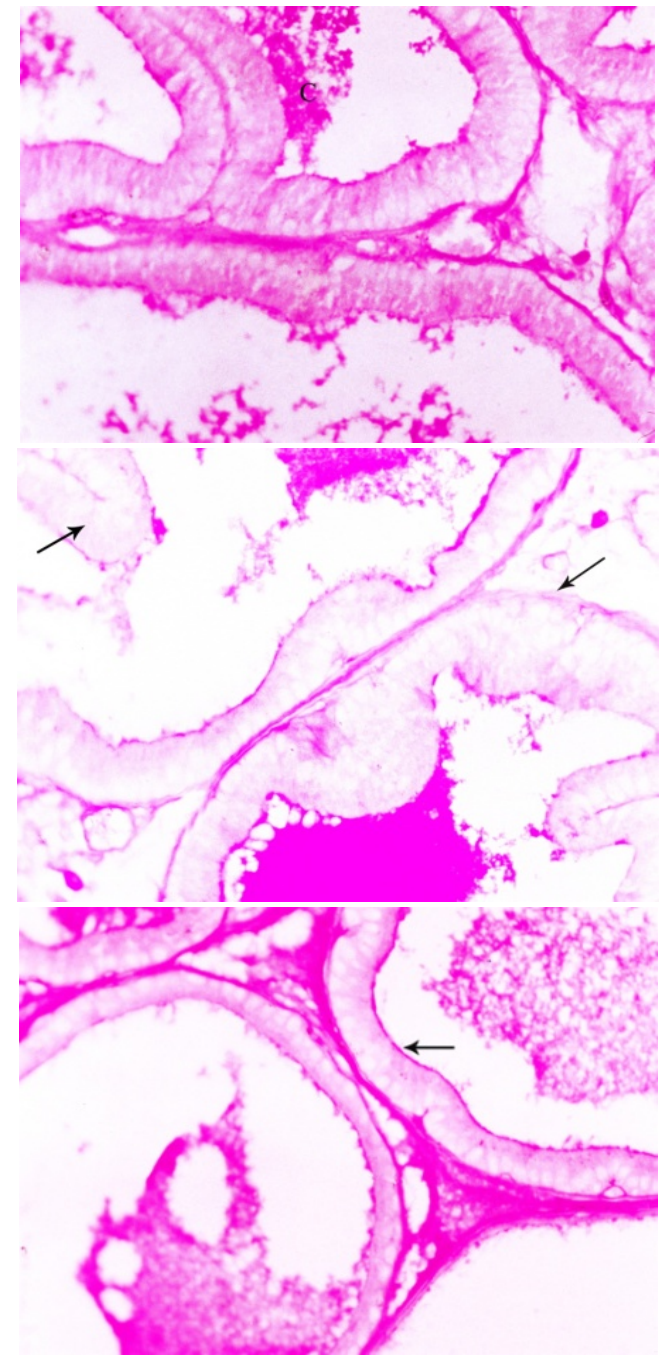

Figure 6. Prostatic acini of (a) a control rat showing PAS-positive materials in the epithelial layers and prostatic concretions (C), (b) a rat treated with carbimazole for 8 weeks showing a decrease of PAS-positive materials in the epithelial cells (arrows) and (c) a rat treated with carbimazole and selenium for 8 weeks showing improvement of PAS-positive materials (arrow), (PAS reaction, $\mathrm{X} 400$ )

\subsubsection{Total Proteins}

Total proteins appeared in the prostate of control rats as deeply stained granules in the cytoplasm and nuclei of the epithelial cells (Fig. 7 a). Animals treated with carbimazole showed a noticeable decrease in the protein content (Fig. 7b). Animals treated with carbimazole and selenium revealed that the epithelial cells contained a somewhat normal content of total proteins (Fig. 7c).

\subsubsection{Nucleic Acids (DNA \& RNA)}

In the epithelial cells of prostate of control rat, DNA present in the nuclei as granules of magenta colour, while RNA was shown as blue fine granules in the cytoplasm of these cells (Fig. 8a). RNA and DNA-containing particles were markedly decreased in the epithelial cells after 8 weeks of carbimazole treatment (Fig. 8b). Animals treated with carbimazole and selenium showed an increase in both RNA and DNA-containing particles (Fig.8c).

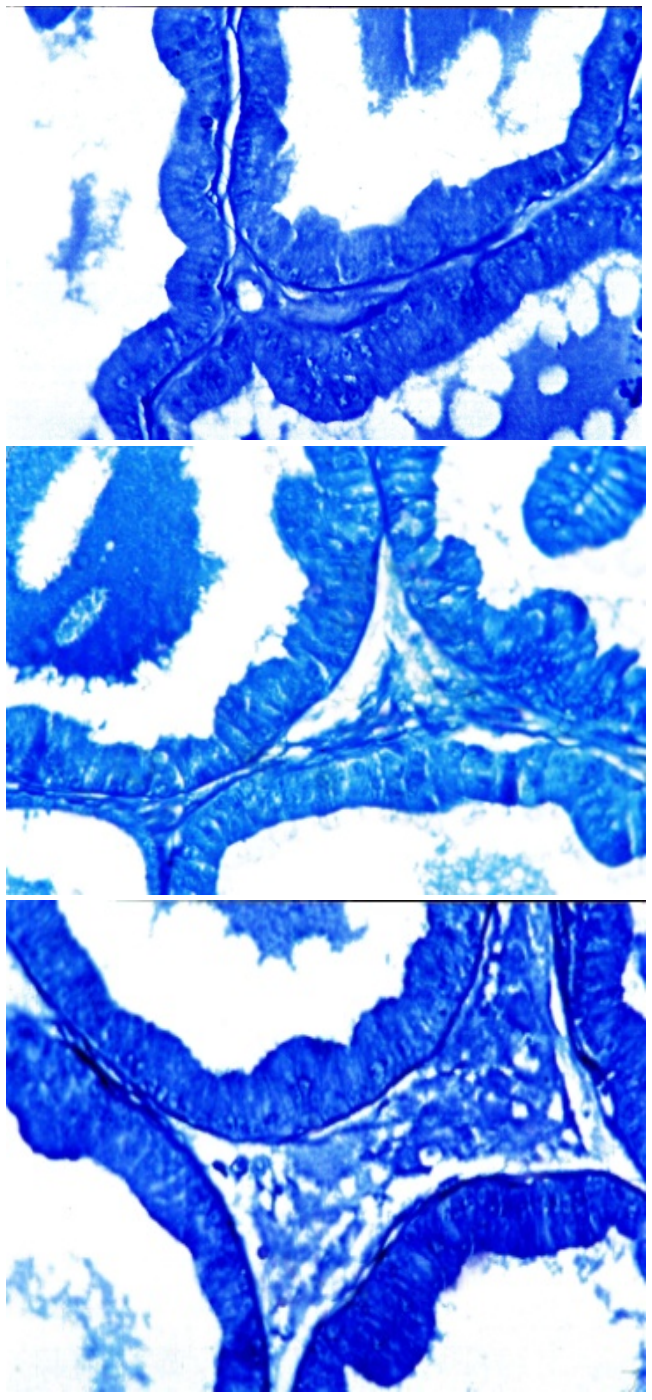

Figure 7. Prostatic acini of (a) a control rat showing normal content and distribution of protein materials in the epithelial layers and prostatic concretions, (b) a rat treated with carbimazole for 8 weeks showing a decrease of total protein materials in the epithelial cells and (c) a rat treated with carbimazole and selenium for 8 weeks showing an increase of total protein materials in the epithelial cells, (Bromophenol blue, X 400)

\section{Discussion}

Results of the present study indicated that carbimazole affected the histological structure of prostate in albino rats. The prostate showed degeneration of epithelial cells, cytoplasmic vacuolization, hyperplasia and congestion of blood vessels. The effect of antithyroid drugs including carbimazole on reproductive system was studied in different animals. Anguiano et al.[22] reported that the enzymatic activity in epididymis, semen and prostate was completely inhibited by 6-n-propyl-2-thiouracil suggesting that local generation of $\mathrm{T}_{3}$ could be associated with the development and function of epididymis and spermatozoa maturation. Marty et al.[23] found that absolute testes, epididymal, prostate and seminal vesicle weights were decreased by 6-propylthiouracil. Also, it significantly decreased serum $\mathrm{T}_{4}$ level. Maran and Aruldhas[24] reported that daily administration of $0.05 \%$ 
methimazole to the nursing mothers induced many changes in newborn male rats; significantly reduced seminiferous tubules diameter, the proliferation and differentiation of germ cells were arrested and their number were decreased.

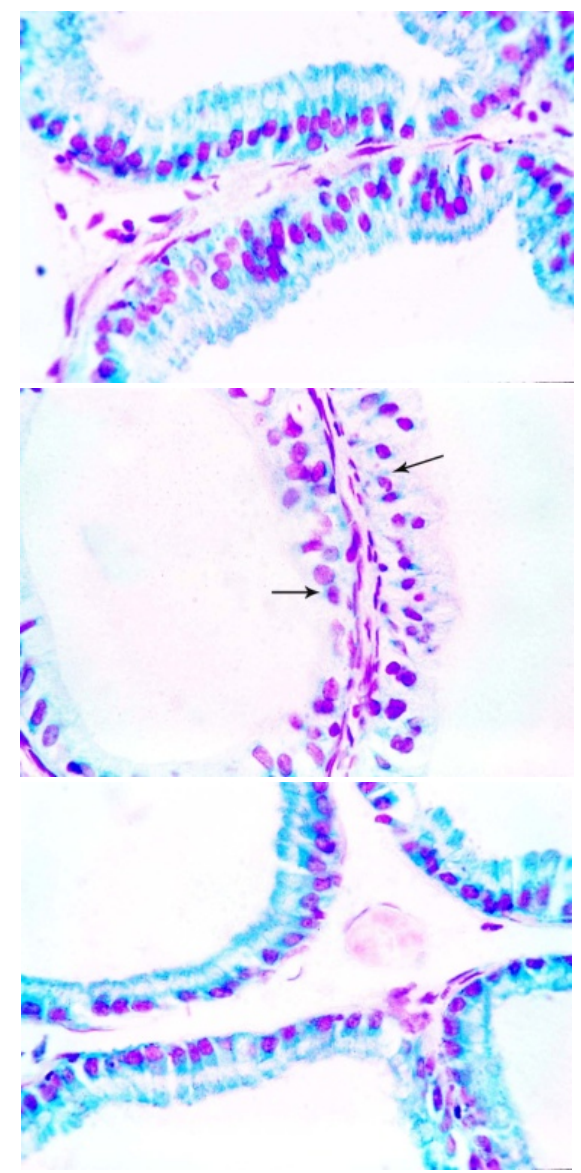

Figure 8. Prostatic acini of (a) a control rat showing normal RNA-containing particles in the epithelial cells, (b) a rat treated with carbimazole for 8 weeks showing marked reduction of RNA-containing particles (arrow) and (c) a rat treated with carbimazole and selenium for 8 weeks showing marked increase of RNA-containing particles, (Schiff-methylene reaction, X 1000)

Treating rat with carbimazole caused reduction in polysaccharides, total proteins and nucleic acids contents in tissue of prostate gland. These results are in agreement with that obtained by some investigators. Palmero et al.[25] reported that oral administration of the anti-thyroid drug methimazole from the day of birth of rats was characterized by a severe retardation of body and testis growth and a net inhibition of the increase in Sertoli cell gammaglutamyl transpeptidase activity as well as in androgen-binding protein and lactate production. These results are consistent with the impairment of protein synthesis in Sertoli cells from hypothyroid rats compared with control. Ram and Waxman[26] concluded that treatment with methimazole led to a $75-85 \%$ depletion of hepatic microsomal $\mathrm{p}^{450}$ reductase activity and protein in both male and female rats. Szanto et al.[27] found that propylthiouracil decreased both hepatic receptor-related protein and low-density-lipoprotein receptor expression in rats. Meisami et al.[28] reported that testicular weight and DNA content were markedly reduced in rat pups administered by propylthiouracil. Carbimazole administration caused a significant decrease of the proliferation, nucleic acids and protein synthesis of the thyroid follicular and adrenocortical cells[29]. Krasilnikova et al.[30] reported that hypothyroidism induced by mercazolil decreased protein kinase $\mathrm{C}$ activity in both membrane and cytosol as well as phospholipid and triacylglycerol synthesis in rat liver.

Oxidative stress is defined as a disruption of the equilibrium between pro- and antioxidant systems. An imbalance between oxidants and antioxidants to produce excess reactive oxygen species can cause oxidative damage in vulnerable targets such as unsaturated fatty acids in membranes, thiol groups in proteins, and nucleic acid bases in DNA. Oxidative damage accumulating during the life cycle and radical-induced damage to vital cellular structures play a key role in the development of many diseases[31]. A number of studies provided evidence for the induction of dose- and time-dependent oxidative stress by carbimazole. Vijayakumar and Nalini[32] indicated that superoxide dismutase, catalase and glutathione peroxidase were reduced in erythrocytes of rats treated with carbimazole compared with control animals. Sakr et al.[16] reported that a high lipid peroxidation with a concomitant decrease in the enzymatic antioxidant status, superoxide dismutase and catalase were recorded in testis of rats treated with carbimazole. Thus, it is suggested that carbimazole induced oxidative stress which resulted in the alterations observed in the prostate.

Concerning the effect of selenium, the present study indicated that selenium improved the histological and histochemical alterations induced by carbimazole. The protective effect of selenium against toxicity of different drugs and chemicals was studied by several investigators. Administration of nicotine caused reduction in sperm count and sperm motility. Activities of testicular enzymes 3 beta hydroxysteroid dehyrogenase and 17beta hydroxysteroid dehyrogenase were decreased. Levels of testosterone in the serum were also reduced. However, the extent of these alterations was lesser in the group administered with nicotine along with selenium[33]. Yu et al.[34] concluded that $0.1 \mathrm{mg} / \mathrm{kg}$ selenium $\left(\mathrm{Na}_{2} \mathrm{SeO}_{3}\right)$ inhibited oxidative stress, apoptosis and cell cycle changes induced by excess fluoride in kidney of rats. Guttenplan et al.[35] showed that the organoselenium compound, 1,4-phenylenebis (methylene) selenocyanate inhibited 4-nitroquinoline-N-oxide-induced tongue tumorigenesis and DNA damage in the tongue of Fisher rats. Kara et al.[36] reported that selenium protected rat testes against cadmium-induced oxidative damage. Jana et al.[37] reported that sodium selenite supplementation significantly protected against exercise-induced testicular gametogenic and spermatogenic disorders, prevented testicular oxidative stress and increased antioxidant status. Kashanian et al.[38] reported that selenium diminished DNA damage induced by incubation of calf thymus DNA with diazinon. Grotto et al.[39] reported that in rats chronically exposed to low levels of methylmercury, selenium co-administration showed a significant reduction in methylmercury-induced genotoxicity, reestablished glutathione peroxidase activity and reduced 
DNA damage. Selenium reduced the cadmium induced histopathological changes in testes of rat, oxidative stress, endocrine disorder and apoptosis[40,41]. On the contrary, Adesiyan et al.[42] reported that selenium had no protective effects against atrazine-induced biochemical alterations in testis and epididymis except testicular lactate dehydrogenase.

It was reported that the mechanism of chemoprotection of selenium may be related to its antioxidant properties as well as its ability to interfere with DNA repair pathways[43]. Sakr et al.[16] revealed that selenium ameliorates testicular toxicity of carbimazole in rats. They added that it enhanced the activities of the antioxidant enzymes (catalase and superoxide dismutase) and reduced lipid peroxidation. In conclusion, selenium treatment was observed to ameliorate the toxicity induced by carbimazole in prostate gland of rats. This effect of selenium may be attributed to its antioxidant effect.

\section{REFERENCES}

[1] Abbassy, A. A., Kamel, S. S., Assaad, S. N., Eid, W. E., 1997, Ultrasonographic and doppler study of the thyroid gland in Graves' disease before and after treatment with antithyroid drugs. Endocrinol. Pract., 3(4), 225-230

[2] Frenais, R., Burgaud, S., Horspool, L. J., 2008, Pharmacokinetics of controlled-release carbimazole tablets support once daily dosing in cats. J. Vet. Pharmacol. Ther., 31(3), 213-219

[3] Ali, B. H., Bashir, A. A., Tanira, M. O., 1995, The effect of thyroxine or carbimazole treatment on gentamicin nephrotoxicity in rats. Hum. Exp. Toxicol., 14(1), 13-17

[4] Marazuela, M., De Paco, G. S., Jlmenez, I., Carraro, R., Fernandez-Herrera, J., Pajares, J. M., Gomez-Pan, A., 2002, Acute pancreatitis, hepatic cholestasis and erythema nodosum induced by carbimazole treatment for Graves' disease. Endocrinol. J., 49(3), 315-318

[5] Zaidi, T. M., Khan, A. A., Hasan, B. M., Faruqi, A. N., 2004, Carbimazole induced thyroid histopathy in albino rats during development. J. Anat. Soc. Ind., 53(2), 14-17

[6] Calañas-Continente, A., Espinosa, M., Manzano-García, G., Santamaría, R., Lopez-Rubio, F., Aljama, P., 2005, Necrotizing glomerulonephritis and pulmonary hemorrhage associated with carbimazole therapy. Thyroid, 15(3), 286-288

[7] Vilchez, F. J., Torres, I., Garcia-Valero, A., López-Tinoco, C., de Los Santos, A., Aguilar-Diosdado, M., 2006, Concomitant a granulocytosis and hepatotoxicity after treatment with carbimazole. Ann. Pharmacother., 40(11), 2059-2063

[8] El-Tayeb. A., liu, A., Ganl, Q., Liu, H., Xu, H., 2004, Antagonistic effect of scutellarin on the toxicity of selenium in rat liver. Biol. Trace Elem. Res., 98(3), 253-258

[9] Gärtner, R., 2009, Selenium and thyroid hormone axis in critical ill states:an overview of conflicting view points. J. Trace Elem. Med. Biol., 23(2), 71-74

[10] Thirunavukkarasu, C., and Sakthisekaran, D., 2003, Sodium selenite, dietary micronutrient, prevents the lymphocyte DNA damage induced by N-nitrosodiethylamine and phenobarbital promoted experimental hepatocarcinogenesis. J. Cell Biochem., 88(3), 578-588

[11] Rayman, M. P., 2005, Selenium in cancer prevention: a review of the evidence and mechanism of action. Proc. Nutr. Soc., 64, 527-542

[12] McCormick, D. L., Rao, K. V., Johnson, W. D., Bosland, M. C., Lubet, R. A., Steele, V. E., 2010, Null activity of selenium and vitamin e as cancer chemopreventive agents in the rat prostate. Cancer Prev. Res. (Phila)., (3), 381-392

[13] Liao, Y., Lu, X., Lu, C., Li, G.;, Jin, Y., Tang, H., 2008, Selection of agents for prevention of cisplatin-induced hepatotoxicity. Pharmacol. Res., 57(2), 125-131

[14] El-Shenawy, S. M., and Hassan, N. S., 2008, Comparative evaluation of the protective effect of selenium and garlic against liver and kidney damage induced by mercury chloride in the rats. Pharmacol. Rep., 60(2), 199-208

[15] Jihen, el H., Imed, M., Fatima. H., Abdelhamid, K., 2008, Protective effects of selenium (Se) and zinc $(\mathrm{Zn})$ on cadmium (Cd) toxicity in the liver and kidney of the rat: histology and Cd accumulation. Food Chem. Toxicol., 46(11), 3522-3527

[16] Sakr, S. A., Mahran, H. A., Nofal, A. E., 2011, Effect of selenium on carbimazole-induced testicular damage and oxidative stress in albino rats. J. Trace Elem. Med. Biol., 25, 59-66

[17] G. E. Paget and J. M. Barnes, Toxicity Tests in Evaluation of Drug Activities Pharmacometries, D. R. Laurence and A. L. Bacharach, Eds., London and New York: Academic Press, 1964

[18] Swathy, S. S., Panicker, S., Indira, M., 2006, Effect of exogenous selenium on the testicular toxicity induced by ethanol in rats. Ind. J. Physiol. Pharmacol., 50(3), 215-224

[19] J. A. Kiernan, Ed., Histological and Histochemical Methods, Theory and Practice. New York, USA: Pergamon Press, 1981

[20] A.G.E. Pearse, Ed., Histochemistry, Theoretical and Applied, London: Churchill Livingstone, 1972

[21] Garvin, A. J., Hall, B. J., Brissie, R. M., Spicer, S. S., 1976, Cytochemical differentiation of nucleic acids with Schiff-methylene blue sequence. J. Histochem. Cytochem., 24, 587-590

[22] Anguiano, B., Aranda, N., Delgado, G., Aceves, C., 2008, Epididymis expresses the highest 5'-deiodinase activity in the male reproductive system: kinetic characterization, distribution and hormonal regulation. Endocrinology 149(8), 4209-4217

[23] Marty, M. S., Crissman, J. W., Carney, E. W., 2001, Evaluation of the male pubertal assay's ability to detect thyroid inhibitors and dopaminergic agents. Toxicol. Sci., 60(1), 63-76

[24] Maran, R. R., and Aruldhas, M. M., 2002, Adverse effects of neonatal hypothyroidism on Wistar rat spermatogenesis. Endocrinol. Res., 28(3), 141-154

[25] Palmero, S., de Marchis, M., Gallo, G., Fugassa, E., 1989, Thyroid hormone affects the development of Sertoli cell function in the rat. J. Endocrinol., 123(1), 105-111 
[26] Ram, P. A., and Waxman, D. J., 1992, Thyroid hormone stimulation of NADPH P450 reductase expression in liver and extrahepatic tissue. Regulation by multiple mechanisms. J. Biol. Chem.,267(5), 3294-3301

[27] Szanto, A., Balasubramaniam, S., Roach, P. D., Nestel, P. J., 1992, Modulation of the low density lipoprotein receptor related protein and its relevance to chylomicron-remnant metabolism. Biochem. J., 288 (Pt3), 791-914

[28] Meisami, E., Najafi, A., Timiras, P. S., 1994, Enhancement of seminiferous tubular growth and spermatogenesis in testes of rats recovering from early hypothyroidism: a quantitative study. Cell Tissue Res., 275(3), 503-511

[29] Mori, F. I., 2000, Autoradiographic and karyometric studies on the effect of carbimazole on the thyroid and adrenal glands in male albino rat. Horm. Metab. Res., 14, 203

[30] Krasilnikova, O. A., Kavok, N. S., Babenko, N. A., 2002, Drug-induced and postnatal hypothyroidism impairs the accumulation of diacylglycerol in liver and liver cell plasma membranes. BMC Physiol., 16, 2-12

[31] H. Sies, Ed., Oxidative Stress Introductory Remark. In: Oxidative Stress. Siers, H. Ed., London: Academic Press, 1985.

[32] Vijayakumar, R. S., and Nalini, N., 2006, Efficacy of piperine, an alkaloidal constituent from piper nigrum on erythrocyte antioxidant status in high fat diet and antithyroid drug induced hyperlipidemic rats. Cell Biochem. Funct., 24(6), 491-498.

[33] Seema, P., Swathy, S. S., Indira, M., 2007, Protective effect of selenium on nicotine-induced testicular toxicity in rats. Biol. Trace Elem. Res., 120 (1-3), 212-218

[34] Yu, R. A., Xia, T., Wang, A. G., Chen, X. M., 2006, Effects of selenium and zinc on renal oxidative stress and apoptosis induced by fluoride in rats. Biomed. Environ. Sci., 19(6), 439-444

[35] Guttenplan, J., Chen, K. M., Khmelnitsky, M., Kosinska, W., Hennessy, J., Bruggeman, R., Desai, D., Amin, S., Sun, Y. W., Spratt, T. E., El-Bayoumy, K., 2007, Effects of 1, 4-phenylenebis (methylene) selenocyanate on mutagenesis and $\mathrm{p} 53$ protein expression in the tongue of lacI rats treated with 4-nitroquinoline-N-oxide. Mutat. Res., 634 (1-2), 146-155

[36] Kara, H., Cevik, A., Konar, V., Dayangac, A., Yilmaz, M., 2007, Protective effects of antioxidants against cadmium-induced oxidative damage in rat testes. Biol. Trace Elem. Res., 120(1-3), 205-211

[37] Jana, K., Samanta, P. K., Manna, I., Ghosh, P., Singh, N., Khetan, R. P., Ray, B. R., 2008, Protective effect of sodium selenite and zinc sulfate on intensive swimming-induced testicular gamatogenic and steroidogenic disorders in mature male rats. Appl. Physiol. Nutr. Metab., 33(5), 903-914

[38] Kashanian, S., Gholivand, M. B., Ahmadi, F., Ravan, H., 2008, Interaction of diazinon with DNA and the protective role of selenium in DNA damage. DNA Cell Biol., 27(6), 325-532

[39] Grotto, D., Barcelos, G. R., Valentini, J., Antunes, L. M., Angeli, J.P., Garcia, S. C., Barbosa, F. Jr., 2009, Low levels of methylmercury induce DNA damage in rats: protective effects of selenium. Arch. Toxicol., 83(3), 249-254

[40] Li, J.L., Gao, R., Li, S., Wang, J.T., Tang, Z.X., Xu, S.W., 2010, Testicular toxicity induced by dietary cadmium in cocks and ameliorative effect by selenium. Biometals, 23(4), 695-705

[41] El-Maraghy, S.A., and Nassar, N.N., 2011, Modulatory effects of lipoic acid and selenium against cadmium-induced biochemical alterations in testicular steroidogenesis. J. Biochem. Mol. Toxicol., 25(1), 15-25

[42] Adesiyan, A. C., Oyejola, T. O., Abarikwu, S. O., Oyeyemi, M. O., Farombi, E. O., 2011, Selenium provides protection to the liver but not the reproductive organs in an atrazine-model of experimental toxicity. Exp. Toxicol. Pathol., 63(3), 201-207

[43] Santos, R. A., and Takahashi, C. S., 2008, Anticlastogenic and antigenotoxic effects of selenomethionine on doxorubicin-induced damage in vitro in human lymphocytes. Food Chem. Toxicol., 46(2), 671-677 